\title{
Overshadowing of the less salient of two novel fluids in a taste-aversion paradigm*
}

\author{
GAYE P. LINDSEY $\dagger$ and PHILLIP J. BEST \\ University of Virginia, Charlottesville, Virginia 22901
}

\begin{abstract}
Rats were made ill by injection of apomorphine following consumption of two novel-tasting fluids (saccharin and vanilla), presented serially in counterbalanced order. On a subsequent preference test between saccharin and a familiar orange fluid, the animals showed a conditioned aversion to the saccharin. However, when vanilla was paired with orange, the animals behaved similarly to the unpoisoned controls. Evidently, the presence of the more salient saccharin during conditioning interfered with the ability of the vanilla to acquire aversive properties.
\end{abstract}

Animals made ill following ingestion of distinctively flavored fluids will quickly learn to avoid consuming those fluids (Garcia, Ervin, \& Koelling, 1966). Ingested substances differ in their ability to be so conditioned. For example, when rats are presented with a novel and a familiar taste and subsequently made ill, they will avoid consuming the more novel taste. This is true even if the familiar taste is presented closer to the illness in time (Revusky \& Bedarf, 1967; Ahlers \& Best, 1971). It has also been demonstrated that an animal that has undergone recent gastrointestinal distress will show neophobia, an aversion to all novel fluids (Rozin, 1968). Neophobia, then, results from prior gastrointestinal distress, but has nothing to do with the association of that distress with particular tastes. No conditioning is involved. The ease of conditioning novel fluids, however, has been attributed to the fact that novelty enhances the salience of a taste and therefore facilitates the conditioning of that particular taste.

It is quite possible that the aversion to the novel fluids attributed to conditioning is due to generalized neophobia and not to conditioning of specific novel tastes. However, a 24-h delay of illness will elminate the aversion (Smith, Taylor, Morris, \& Hendricks, 1965). An attempt by Scarborough, Whaley, and Rogers (1964) to establish an aversion with backward conditioning was unsuccessful. In other words, preceding the novel taste by illness did not lead to an aversion to that taste. If neophobia was sufficient to explain the acquired aversion to novel fluids, aversions should have developed in both of these instances.

It is also quite possible that novelty itself is conditioned. That is, rather than merely facilitating the conditioning of a particular taste, the novelty of the

*This report is based upon a thesis submitted by the first author to the University of Virginia in partial fulfillment of the requirements for the MA degree. The research was supported by United States Public Health Service Grant MH 16478. Requests for reprints should be sent to Phillip J. Best, Department of Psychology, Gilmer Hall, University of Virginia, Charlottesville, Virginia 22901.

†Current address: Madeira School, Greenway, Virginia 22067. taste is the cue property that is conditioned. If such is the case, then conditioning the animal should generalize the aversion to other novel tastes. Nachman (1963) has shown that a learned aversion for $\mathrm{LiCl}$ will generalize to other salts whose tastes are highly confusable with $\mathrm{LiCl}$ and also novel, but not to highly dissimilar salts or familiar tastes. This suggests that while the phenomenon is in part due to a specific taste aversion, a more general aversion is also learned. The basis of this general aversion must be novelty, since familiar tastes (even similar ones) are not aversive. However, novelty is not the only quality that is conditioned, since dissimilar-tasting novel solutions were not avoided.

Kalat and Rozin (1970) found that animals presented with two novel fluids prior to illness will tend to avoid one of these fluids and consume the other when subsequently tested for a preference between those same two fluids. They entertained three possible reasons why one of the fluids would be more easily conditioned (or more salient) than the other. The level of salience might depend on intrinsic taste properties of the fluids, the intensity of the taste stimuli, and/or the relative novelty of the two tastes. Their results indicate that novelty as a cue property is not solely responsible for conditioning.

The purpose of this study was to approach the question of salience in a different manner from that of Kalat and Rozin. In their paradigm, animals were made ill following ingestion of two novel tastes and on the following day a preference test was given between those same two tastes. Conceivably, an aversion was formed to both tastes, but of differing intensity. An animal that has been deprived of water for several days might simply be picking the "lesser of two evils" out of desperation.

In order to determine the specificity of conditioning under the conditions used by Kalat and Rozin, the animals in the current study were conditioned with two novel fluids, presented serially in a counterbalanced order, and then tested for the conditioned aversion by being given a choice between either of these two fluids and a third familiar fluid. It was reasoned that even though one of the fluids might be more salient than the other, novelty itself might have been conditioned or a generalized neophobia might have been formed. If either 
Table 1

Mean and Range of the Ratio of Novel Fluid to Total Fluid Consumed When Either of the Novel Fluids (Vanilla or Saccharin) Was Presented With a Familiar Orange Extract Solution*

\begin{tabular}{lccccc}
\hline & \multicolumn{2}{c}{ Saline } & & \multicolumn{2}{c}{ Apomorphine } \\
\cline { 2 - 3 } & Vanilla & Saccharin & & Vanilla & Saccharin \\
\hline First & .43 & .71 & & .59 & .21 \\
Fluid & $(.25-.55)$ & $(.57-.83)$ & & $(.43-.86)$ & $(.14-.31)$ \\
Presented & & & & .47 & .26 \\
Second & .41 & .51 & & .47 & \\
Fluid & $(.19-.39)$ & $(.30-.73)$ & & $(.27-.64)$ & $(.20-.33)$ \\
Presented & .42 & .62 & & .54 & .23 \\
Total & $(.19-.55)$ & $(.30-.83)$ & $(.27-.86)$ & $(.14-.33)$ \\
\hline
\end{tabular}

*During conditioning, animals received either vanilla or saccharin first, followed by saccharin or vanilla, respectively, and subsequently were given an injection of saline or apomorphine.

is the case, then the less salient fluid should also be avoided when presented with the familiar solution. On the other hand, if the conditioning is specific to one of the tastes, then the presence of that taste might mask or overshadow the other taste and diminish its ability to acquire aversive properties.

\section{PROCEDURE AND EXPERIMENTAL DESIGN}

Twenty-four male Sprague-Dawley-derived rats, weighing between 225 and $350 \mathrm{~g}$, were placed on a $24-\mathrm{h}$ water-deprivation schedule. One animal died during the experiment. All were housed individually in $10 \times 7 \times 7$ in. wire mesh cages with constant access to Purina Lab Chow. The only fluids available during the experiment were the test solutions, which were presented at the same time each day in the drinking cages. The drinking cages were identical to the home cages except for mountings which enabled three Richter tubes to be attached to the front, in the center, and about 2 in. right or left of center. When only one fluid was presented, it was always placed in the center position. Two fluids given simultaneously were placed in the two outer positions. A food cup with pellets was also present, wired to the floor at the back of the cage. The Richter tubes had a capacity of $100 \mathrm{ml}$ and were calibrated in milliliters.

A 2 by 2 by 2 factorial design was used, varying presentation order, illness, and novel solution presented on test day. On the first 3 days, animals were placed in the drinking cages for $20 \mathrm{~min}$ access to a $.08 \%$ solution of orange extract. On the 4 th day, half of the animals received $2 \mathrm{~min}$ access to $0.08 \%$ vanilla, followed by $2 \mathrm{~min}$ access to $.15 \%$ saccharin. The order was reversed for the other half. Pilot studies (Lindsey, 1971) had shown that the animals could recognize and discriminate these concentrations and that the saccharin was more salient than the vanilla. Immediately following the second fluid, half of each group was injected with apomorphine $(15 \mathrm{mg} / \mathrm{kg}$, IP). The remaining animals received an equal-volume saline injection (isotonic). On the 5th day, all animals were given a choice of orange and either saccharin or vanilla for $20 \mathrm{~min}$.

\section{RESULTS AND DISCUSSION}

The data reveal that vanilla did not acquire aversive properties but that saccharin did. Results are shown in Table 1 . The data were analyzed using a Mann-Whitney $\mathrm{U}$ test. Comparisons of presentation order in both the apomorphine and saline groups yielded no significant differences $\left(n_{1}=7, n_{2}=5, U=16, p \approx .44 ; n_{1}=6\right.$, $\left.\mathrm{n}_{2}=5, \mathrm{U}=12, \mathrm{p} \approx .66\right)$. Other analyses are collapsed over presentation order. No significant difference was found between apomorphine and saline groups tested on orange vs vanilla $\left(\mathrm{n}_{1}=7, \mathrm{n}_{2}=7, \mathrm{U}=15, \mathrm{p} \approx .87\right)$, indicating that vanilla did not acquire aversive properties. In fact, the animals given apomorphine showed a slightly higher consumption of vanilla than did controls.

A significant difference was found between apomorphine and saline groups tested on orange vs saccharin $\left(\mathrm{n}_{1}=4, \mathrm{n}_{2}=5, \mathrm{U}=2, \mathrm{p}<.03\right)$, thus demonstrating that saccharin had acquired aversive properties. Further, preference for saccharin exceeded preference for vanilla in control animals $\left(n_{1}=7, n_{2}=4\right.$, $U=5, p \approx .06)$, but in conditioned animals saccharin was found to be significantly more aversive than vanilla $\left(\mathrm{n}_{1}=7, \mathrm{n}_{2}=5, \mathrm{U}=2, \mathrm{p}<.01\right)$.

An aversion was never developed to vanilla, even when it had been the second novel fluid and therefore more nearly contiguous with poisoning. Saccharin was avoided by every conditioned animal, regardless of presentation order. So, even under conditions which allow for the overt demonstration of an aversion to the less salient solution, no aversion was found. Thus, the less salient solution must have been ingested not only by virtue of its being the "lesser of two evils," but actually because it never acquired aversive properties. Apparently, the less salient of two novel tastes is not associated with illness at all when the two tastes are paired, regardless of presentation order.

As Kalat and Rozin (1970) have pointed out, the overshadowing or masking of less salient stimuli by more salient stimuli has been found in studies using exteroceptive stimuli (Kamin, 1969). In Kamin's studies, more intense stimuli tended to be more salient. Also, the salience of a stimulus could be reduced by nonreinforced presentations of that stimulus prior to conditioning or by introducing that stimulus during later conditioning trials of another stimulus.

The data do not necessarily imply that vanilla is generally less salient than saccharin, but that it is so in the concentrations used in this experiment. These results confirm the Kalat and Rozin study in suggesting again that salience is dependent upon the cue properties of a taste and is relatively unaffected by temporal contiguity.

\section{REFERENCES}

Ahlers, R. H., \& Best, P. J. Novelty versus temporal contiguity in learned taste aversions. Psychonomic Science, 1971, 25, 34-36.

Garcia, J., Ervin, F. R., \& Koelling, R. A. Learning with prolonged delay of reinforcement. Psychonomic Science, 1966, 5, 121-122.

Kalat, J. W., \& Rozin, P. "Salience": A factor which can override temporal contiguity in taste-aversion learning. Journal of Comparative \& Physiological Psychology, 1970, 71; 192-197. 
Kamin, L. J. Predictability, surprise, attention and conditioning. In B. A. Campbell and R. M. Church (Eds.), Punishment and aversive behavior. New York: Appleton Century Crofts, 1969.

Lindsey, G. P. The role of cue additivity in salience in the taste aversion paradigm. Unpublished master's thesis, University of Virginia, October 1971.

Nachman, M. Learned aversion to the taste of lithium chloride and generalization to other salts. Journal of Comparative \& Physiological Psychology, 1963, 56, 343-349.

Revusky, S. H., \& Bedarf, E. W. Association of illness with prior ingestion of novel foods. Science, 1967, 155, 219-220.

Rozin, P. Specific aversions and neophobia resulting from vitamin deficiency or poisoning in half wild and domestic rats.
Journal of Comparative \& Physiological Psychology, 1968, 66, 82-88.

Scarborough, B. E., Whaley, D. L., \& Rogers, J. G. Saccharin avoidance behavior instigated by X-irradiation in backward conditioning paradigms. Psychological Reports, 1964, 14, $475-481$.

Smith, J. C., Taylor, H. L., Morris, D. D., \& Hendricks, J. Further studies of X-ray conditioned saccharin aversion during the postexposure period. Radiation Research, 1965, 24, $423-431$.

(Received for publication August 14, 1972; accepted September 7, 1972.) 